\title{
Energy-harvesting bio-electro-dehalogenation for sustainable wastewater treatment
}

Huang, Li-Zhi; Zhang, Yifeng; Hu, Xin-Ming; Hansen, Hans Christian B.; Pedersen, Steen Uttrup; Daasbjerg, Kim

Published in:

Electrochimica Acta

Link to article, DOI:

10.1016/j.electacta.2018.09.056

Publication date:

2018

Document Version

Peer reviewed version

Link back to DTU Orbit

Citation (APA):

Huang, L-Z., Zhang, Y., Hu, X-M., Hansen, H. C. B., Pedersen, S. U., \& Daasbjerg, K. (2018). Energy-harvesting bio-electro-dehalogenation for sustainable wastewater treatment. Electrochimica Acta, 290, 38-45.

https://doi.org/10.1016/j.electacta.2018.09.056

\section{General rights}

Copyright and moral rights for the publications made accessible in the public portal are retained by the authors and/or other copyright owners and it is a condition of accessing publications that users recognise and abide by the legal requirements associated with these rights.

- Users may download and print one copy of any publication from the public portal for the purpose of private study or research.

- You may not further distribute the material or use it for any profit-making activity or commercial gain

- You may freely distribute the URL identifying the publication in the public portal

If you believe that this document breaches copyright please contact us providing details, and we will remove access to the work immediately and investigate your claim 


\section{Accepted Manuscript}

Energy-harvesting bio-electro-dehalogenation for sustainable wastewater treatment

Li-Zhi Huang, Yifeng Zhang, Xin-Ming Hu, Hans Christian B. Hansen, Steen Uttrup Pedersen, Kim Daasbjerg

PII: $\quad$ S0013-4686(18)32028-0

DOI: $\quad$ 10.1016/j.electacta.2018.09.056

Reference: $\quad$ EA 32581

To appear in: Electrochimica Acta

Received Date: 22 May 2018

Revised Date: 22 August 2018

Accepted Date: 8 September 2018

Please cite this article as: L.-Z. Huang, Y. Zhang, X.-M. Hu, H.C.B. Hansen, S.U. Pedersen, K. Daasbjerg, Energy-harvesting bio-electro-dehalogenation for sustainable wastewater treatment, Electrochimica Acta (2018), doi: 10.1016/j.electacta.2018.09.056.

This is a PDF file of an unedited manuscript that has been accepted for publication. As a service to our customers we are providing this early version of the manuscript. The manuscript will undergo copyediting, typesetting, and review of the resulting proof before it is published in its final form. Please note that during the production process errors may be discovered which could affect the content, and all legal disclaimers that apply to the journal pertain. 


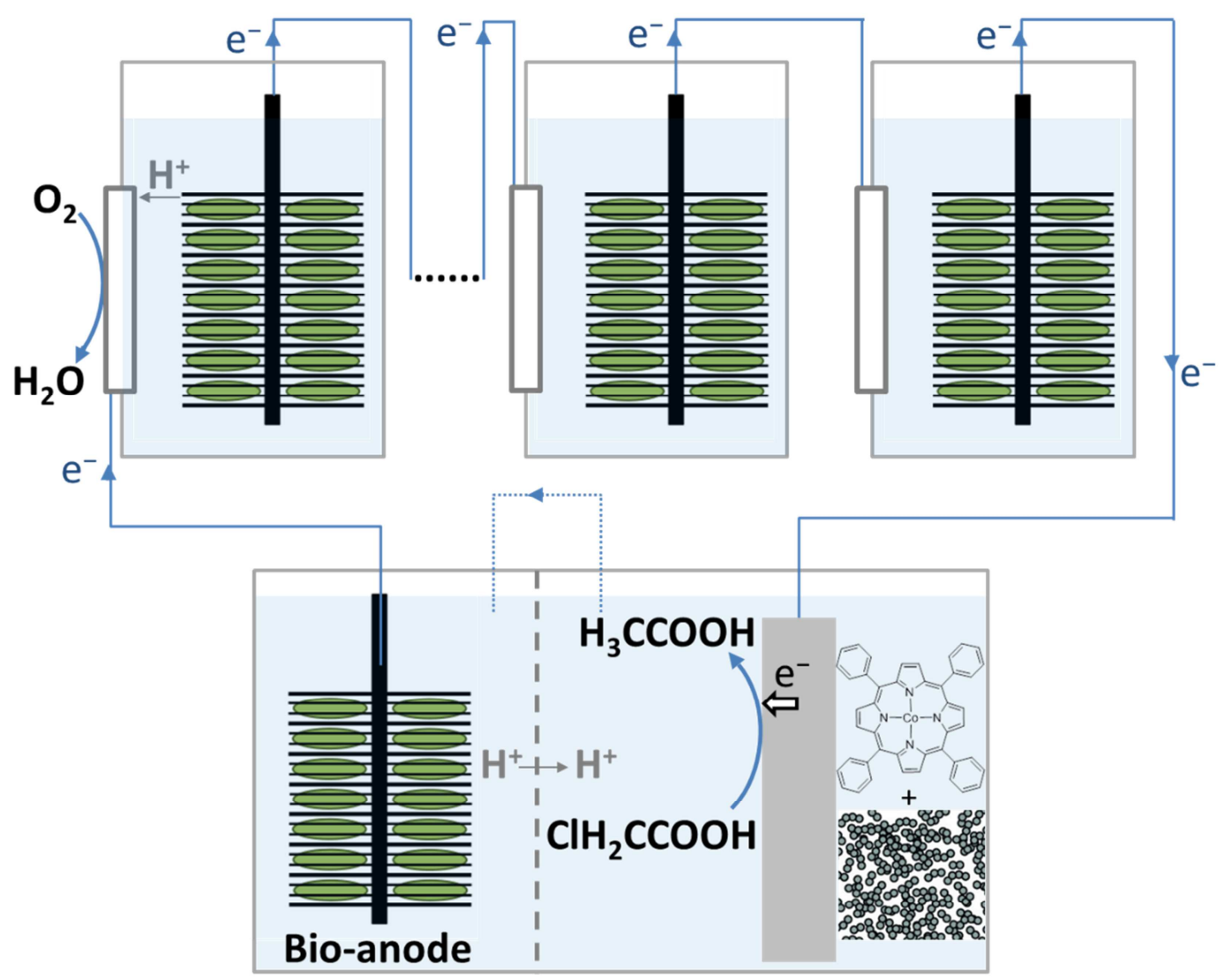




\section{Energy-harvesting bio-electro-dehalogenation}

\section{for sustainable wastewater treatment}

Li-Zhi Huang, ${ }^{\text {a,b,c }}$ Yifeng Zhang, ${ }^{* d}$ Xin-Ming Hu, ${ }^{\mathrm{b}}$ Hans Christian B. Hansen, ${ }^{\mathrm{c}}$ Steen Uttrup Pedersen, ${ }^{\mathrm{b}}$ and Kim Daasbjerg ${ }^{\mathrm{b}}$

${ }^{a}$ School of Civil Engineering, Wuhan University, No. 8, East Lake South Road, Wuhan, P.R. China

${ }^{b}$ Interdisciplinary Nanoscience Center ( $i N A N O$ ) and Carbon Dioxide Activation Center, Aarhus University, Gustav Wieds Vej 14, DK-8000 Aarhus C, Denmark

${ }^{c}$ Department of Plant and Environmental Sciences, University of Copenhagen, Thorvaldsensvej 40, DK-1871 Frederiksberg C, Denmark

${ }^{d}$ Department of Environmental Engineering, Technical University of Denmark, DK2800, Lyngby, Denmark

E-mails:yifz@env.dtu.dk(Y.Zhang); huxm@inano.au.dk(X.-M.Hu) 


\section{Abstract}

The concept of an "energy-harvesting bio-electro-dehalogenation" process is demonstrated, where exoelectrogenic bacteria in an anodic chamber of a microbial fuel cell (MFC) are used to capture and exploit the electrical energy stored in the biodegradable substrate (acetate). The acetate was derived from full electrocatalytic dehalogenation of non-biodegradable halogenated organic compounds (haloacetic acids) in the cathodic chamber. Cobalt(II) meso-tetraphenylporphyrin serves the role as electrocatalyst in the MFC. Cyclic voltammetric analysis shows that full dehalogenation requires a cathodic potential of $-1.1 \mathrm{~V}$ vs. $\mathrm{Ag} / \mathrm{AgCl}$ which can be augmented by stacked MFCs powered by the dehalogenated products. Cyclic voltammetric analysis and ion chromatography measurement confirm that electrogenerated cobalt(I) mesotetraphenylporphyrin is catalyzing the reduction of tri-, di-, and monochloroacetic acids in a sequential dehalogenation processes. The energy harvesting concept is also applicable to other bio-electrochemical processes for treatment of bio-refractory pollutants.

Keywords: bio-electro-dehalogenation; sustainable wastewater treatment; microbial fuel cell; metal macrocycles catalyst. 


\section{Introduction}

Wastewater treatment comprises energy intensive processes consuming about $15 \mathrm{GW}$, or $3 \%$ of the total electricity produced in the USA $[1,2]$. On the other hand, domestic wastewater contains $\sim 9.3$ times more energy than the amount needed for its treatment in a municipal wastewater treatment plant [3]. Thus, a self-sustainable or even an energyproducing wastewater treatment is theoretically feasible [4]. Microbial fuel cells (MFCs) have been proposed as a mean to capture the energy in biodegradable wastewater components and produce renewable electricity [5, 6]. In MFC, exoelectrogenic bacteria oxidize organic matter in wastewater and generate electrons which are transferred to the anode and flow to the cathode.

In general, bio-refractory wastewater (e.g. wastewater contaminated by halogenated compounds) cannot be treated in the normal low-cost biological process because of a too high toxicity towards bacteria. This kind of wastewater therefore has to be handled separately from normal house-hold wastewater, preventing usually the chemical energy to be captured by MFCs. In contrast, energy-intensive and costly chemical/physical treatment technology has to be applied using strong oxidants to mineralize the biorefractory pollutants $[7,8]$. Unfortunately, the chemical energy stored in the biorefractory pollutant as organic matter is lost during the mineralization, where $\mathrm{CO}_{2}$ and water are produced. Conversion of bio-refractory pollutants to biodegradable compounds is a potential approach for subsequent microbial energy capture via exoelectrogenic bacteria. The captured energy can then be cycled and exploited in the conversion of biorefractory pollutants [4]. 
Haloacetic acids (HAAs) are common environmental contaminants in water introduced through chlorination of drinking water, by degradation of pesticide, and via industrial applications $[9,10]$. HAAs are bio-refractory and tend to accumulate in drinking water and surface water where they are suspected for causing human carcinogenicity at concentrations as low as $60 \mu \mathrm{g} \mathrm{L}^{-1}$ [11]. Reductive dehalogenation is usually used to detoxicate halogenated organic compounds (HOCs) including HAAs. Electrochemical reductive dehalogenation has certain advantages compared to chemical reduction, in that there is no need for handling and storage of strong reductants. At the same time the process controllability and automatization level are both high [12]. The main drawbacks are associated with the need for employing precious metal electrodes and the difficulties in scaling up the process because of inefficient use of the electrical energy.

Direct electroreductive dehalogenation at electrodes takes place at potentials where substantial water reduction occurs, leading to a very low current efficiency for the halogenated compounds. Therefore, development of a cost-effective catalyst consisting of earth-abundant elements and possessing high catalytic activity to lower the overpotential for electroreductive dehalogenation would be crucial for future applications [12]. In this respect, it is inspiring to watch Nature's approach in terms of some unique microbiological reductive dehalogenation processes mediated by metal macrocyclesfeatured coenzymes such as coenzyme $\mathrm{F}_{430}$, vitamin $\mathrm{B}_{12}$, and hematin [13-17]. In fact, vitamin $\mathrm{B}_{12}$ mimicking cobalt macrocycles have been reported to be some of the most effective catalysts among various metal macrocycles due to their low spin electronic configurations [13]. 
Two challenges remain for developing large-scale application of electrocatalytic reductive dehalogenation, i.e. finding a cheap, earth-abundant, and highly reactive electrocatalyst together with reducing the operational cost. In principle, utilization of biogenerated electrons in a MFC could drive the electrocatalytic reductive dehalogenation with the assistance of a metal macrocycles catalyst. Removal of bio-refractory contaminants has been demonstrated using the bio-electro-Fenton reaction where electrogenerated $\mathrm{H}_{2} \mathrm{O}_{2}$ reacts with $\mathrm{Fe}^{2+}$ to generate highly oxidative hydroxyl radicals [18]. Though promising, this process is still in its infancy and accompanied with many practical problems (e.g., low selectivity and requirement of extra chemicals), let alone that the chemical energy of bio-refractory contaminants is lost or wasted. The disadvantages of using the MFC-Fenton (or other bio-electro-Fenton systems) for dehalogenation compared to the bio-electro-reductive dehalogenation proposed in this work may be summarized as follows: i) the active hydroxyl radicals $\bullet \cdot \mathrm{OH}$ readily react with other molecules, thus, lowering the efficiency of the HOCs oxidation; ii) oxidation of iron(II) results in sludge generation; iii) the low level of dissolved $\mathrm{O}_{2}$ in water leads to inefficiency of the electrochemical $\mathrm{H}_{2} \mathrm{O}_{2}$ production. Means to increase the efficiency of $\mathrm{H}_{2} \mathrm{O}_{2}$ production in terms of air bubbling and using a $\mathrm{Pt}$ catalyst increase both the operation and manufacture cost of the system; and iv) the produced iron(II) and $\mathrm{H}_{2} \mathrm{O}_{2}$ are second contaminations which makes the setup impractical for drinking water treatment. In contrast, direct utilization of bio-generated electricity for reductive dehalogenation as described here does not encounter these problems. The biodegradation of organic compounds (derived from bio-refractory compounds in the cathodic compartment) in the 
anode chamber can provide protons and electrons needed for the reduction of pollutants at the cathode, which makes it an ideal process for self-powered treatment.

In this work, our aims are to i) reduce the high cost for construction of an electrochemical reactor by using a cheap catalyst consisting of earth-abundant elements mixed with ordinary carbon black/graphite, ii) lower the energy consumption and reduce the overpotential for HAAs reduction with such novel catalyst, iii) extract and recycle the chemical energy stored in the completely dehalogenated product via MFC, and to iv) investigate the performance of this energy harvesting bio based electro-dehalogenation process and give suggestions on how to optimize this setup in order to further minimize the energy consumption.

\section{Experimental}

Materials. Cobalt(II) meso-tetraphenylporphyrin (Co $\left.{ }^{\mathrm{II}} \mathrm{TPP}\right)$ was purchased from ABCR (Figure S1). Carbon black (VULCAN ${ }^{\circledR}$ XC72R) was from Cabot Corporation. Graphite foil $(1 \mathrm{~mm}$ thick; $2.5 \mathrm{~cm} \times 7 \mathrm{~cm})$ was from Alfa Aesar. Glassy carbon (GC) rods $($ Sigradur $\mathrm{G})$ used to prepare disk electrodes $($ diameter $=1 \mathrm{~mm})$ and $\mathrm{GC}$ plates $(1 \mathrm{~cm} \times 1$ $\mathrm{cm} \times 0.1 \mathrm{~cm}$ ) were supplied by HTW Hochtemperatur-Werkstoffe Gmbh in Germany. The ID $110 \mathrm{~mm}$ cation exchange membrane was from Membranes international Inc. USA. Tri-, di-, and monochloroacetic acids (TCAA, DCAA, MCAA, respectively) and $N, N$-dimethylformamide (DMF) were purchased from Sigma-Aldrich. Tetrabutylammonium tetrafluoroborate $\left(\mathrm{Bu}_{4} \mathrm{NBF}_{4}\right)$ was prepared by mixing a 1:1 molar ratio of sodium tetrafluoroborate obtained from Sigma Aldrich and tetrabutylammonium hydrogensulfate from Fluka. The precipitate was recrystallized in ethyl acetate and 
pentane, and dried under vacuum at $80{ }^{\circ} \mathrm{C}$ [19]. All chemicals were of analytical grade and used without further purification.

Cyclic voltammetry analysis. Cyclic voltammetry was performed in an undivided conventional three-electrode cell using a Pt wire as the counter electrode and a leak-free $\mathrm{Ag} / \mathrm{AgCl}(3.5 \mathrm{M})$ reference electrode. For the homogeneous catalysis study, the CoTPP catalyst was dissolved in $10 \mathrm{~mL}$ DMF containing $0.1 \mathrm{M} \mathrm{Bu}_{4} \mathrm{NBF}_{4}$. A GC disk electrode was used as working electrode. For heterogeneous catalysis studies a GC plate coated with catalyst ink was used as working electrode. The catalyst ink contained $2.5 \mathrm{~g} \mathrm{~L}^{-1}$ CoTPP and $2.5 \mathrm{~g} \mathrm{~L}^{-1}$ carbon black (CB) in DMF. The ink was sonicated for $30 \mathrm{~min}$ followed by drop casting on the electrode at a loading of $40 \mu \mathrm{L} \mathrm{cm}{ }^{-2}$. The effective working area for the GC plate electrode was $0.5 \mathrm{~cm}^{2}$. The electrolyte was $10 \mathrm{~mL} 0.5 \mathrm{M}$ $\mathrm{Na}_{2} \mathrm{SO}_{4}$ aqueous solution.

Dehalogenation in MFC or microbial electrolysis cell (MEC). Figure 1 provides an illustration of the MFC and MEC set-up used for the concomitant energy harvesting and dehalogenation. Each MFC or MEC consists of two round glass chambers (anodic and cathodic chambers) separated by a cation exchange membrane. The anode was made of a carbon fiber brush $(5.9 \mathrm{~cm}$ diameter, $6.9 \mathrm{~cm}$ length, Mill-Rose, USA), which was pretreated at $450{ }^{\circ} \mathrm{C}$ for $30 \mathrm{~min}$ and then pre-cultivated with mature biofilm in the MFC reactor. The taxonomic classification of the bacteria communities in the biofilm was described in a previous study [20]. The growth substrate for the bacteria was $300 \mathrm{~mL} 17$ $\mathrm{mM}$ acetate (AA) dissolved in $50 \mathrm{mM}$ phosphate buffer aqueous solution (PBS, pH 7) amended with nutrient. The nutrient contains (per liter) $0.31 \mathrm{~g} \mathrm{NH}_{4} \mathrm{Cl}, 0.13 \mathrm{~g} \mathrm{KCl}, 12.5$ $\mathrm{mL}$ mineral, and $12.5 \mathrm{~mL}$ vitamin solution (composition shown in Table $\mathrm{S} 1$ ) [5]. The 
growth substrate was bubbled with Ar for $30 \mathrm{~min}$ at a flow rate of $30 \mathrm{~mL} \mathrm{~min}^{-1}$ to achieve anoxic conditions for the bacteria.

The graphite foil coated with CoTPP/CB catalyst was used as cathode in the MFC or MEC. The catalyst ink covered the area of $2.5 \mathrm{~cm} \times 5 \mathrm{~cm}$ on both sides of the graphite foil at a loading of $40 \mu \mathrm{L} \mathrm{cm}^{-2}$. The distance between the anode and cathode electrodes was $3 \mathrm{~cm}$. The catholyte, $\mathrm{O}_{2}$-free $250 \mu \mathrm{M}$ TCAA in $2 \mathrm{mM} \mathrm{Na} \mathrm{SO}_{4}(200 \mathrm{~mL}$ ) was vigorously stirred. A $10 \Omega$ resistor was connected to make the electron counting by monitoring the current in the circuit. For MEC experiments additional voltages of 0.3 and $0.7 \mathrm{~V}$ were applied by a power supply to augment the cathodic potential to $-0.8 \mathrm{~V}$ and $-1.1 \mathrm{~V}$, respectively. A control experiment was conducted at open circuit to exclude the presence of any non-electrochemical reactions, e.g. a chemical reaction between TCAA and CoTPP. Another control experiment was performed using formate as growth medium to exclude the possibility that acetate might diffuse from the anolyte to the catholyte through the cation exchange membrane. All potentials reported are given vs. the $\mathrm{Ag} / \mathrm{AgCl}$ (3.5 M) electrode.

Recyclability of the self-dehalogenation process. The recyclability and the sustainability of the self-dehalogenation process were investigated in a stacked MFC+MEC reactor, where MCAA was reduced to AA in the cathodic compartment of MEC. The MEC-MFC process was operated in batch mode. MCAA was chosen as the target halogenated compound as MCAA is the least susceptible to a reductive dehalogenation among TCAA, DCAA and MCAA (vide infra). MFCs were connected in series to augment the cathodic potential in the MEC (Figure 1c and Text S1). The volume of the medium in the MFC was $300 \mathrm{~mL}$. The catholyte in the MEC consisted of $300 \mathrm{~mL}$ 
$50 \mathrm{mM}$ PBS with $17 \mathrm{mM}$ MCAA. The area of the CoTPP/CB catalyst on graphite foils was $50 \mathrm{~cm}^{2}$. The process was initiated by full conversion of sufficient MCAA to AA in the cathodic chamber of MEC with the cathodic potential augmented by the power supply to approx. $-1.2 \mathrm{~V}$. The fully dehalogenated products were analyzed by IC to ensure the absence of any MCAA residual, amended with nutrient, and then recycled as anolyte in the MFC and MEC. This nutrient-amended anolyte served to generate electricity in MFCs which were stacked to augment the cathodic potential in the MEC (Figure S2 and Figure S3). The power density curves were measured by varying an external resistor in the range of $51-6200 \Omega$.

Analytical methods. The amount of TCAA, DCAA, MCAA, AA, and $\mathrm{Cl}^{-}$in the liquid phase was analyzed with a Metrohm Ion Chromatograph consisting of an 818 IC pump, 820 IC separation centre, 833 IC liquid handler, 819 IC conductivity detector, and a Metrosep A Supp 5 analytical column $(100 \times 4 \mathrm{~mm}$ i.d.). The eluent consisted of $84 \mathrm{mg}$ $\mathrm{L}^{-1} \mathrm{NaHCO}_{3}$ and $339 \mathrm{mg} \mathrm{L}^{-1} \mathrm{Na}_{2} \mathrm{CO}_{3}$ and the flow rate was $0.7 \mathrm{~mL} \mathrm{~min}^{-1}$. The detection limits of TCAA, DCAA, MCAA, AA, and $\mathrm{Cl}^{-}$are $0.1 \mu \mathrm{M}$. The carbon mass balance during the reaction course was calculated as $[\mathrm{TCAA}]+[\mathrm{DCAA}]+[\mathrm{MCAA}]+[\mathrm{AA}]$, and the $\mathrm{Cl}$ balance as $3[\mathrm{TCAA}]+2[\mathrm{DCAA}]+[\mathrm{MCAA}]+\left[\mathrm{Cl}^{-}\right]$.

The Faradaic efficiency for acetate formation via MCAA reduction on the CoTPP/CB cathode ( $\left.\mathrm{FE}_{\text {cathode }}\right)$ was calculated according to eq 1.

$$
\mathrm{FE}_{\text {cathode }}=\frac{n_{1} C_{\mathrm{AA}} V F}{Q}
$$


In this expression, $n_{l}$ is the theoretical number of electrons needed for the reduction of MCAA to AA (i.e. $n_{l}=2$ ), $V$ is the volume of the MCAA containing electrolyte, $F$ is Faraday's constant, and $Q$ is the total electrical charge recorded during the preset time $t$.

The Faradaic efficiency for acetate oxidation via exoelectrogenic bacteria on the anode $\left(\mathrm{FE}_{\text {anode }}\right)$ was calculated by eq 2 .

$$
\mathrm{FE}_{\text {anode }}=\frac{Q}{Q_{\text {substrate }}}
$$

Here, $Q_{\text {substrate }}$ is the theoretical charge produced in the oxidation of AA assuming eq 3 is the only reaction taking place [21].

$$
\mathrm{C}_{2} \mathrm{H}_{4} \mathrm{O}_{2}+2 \mathrm{H}_{2} \mathrm{O} \rightarrow 2 \mathrm{CO}_{2}+8 \mathrm{e}^{-}+8 \mathrm{H}^{+}
$$

Hence, $Q_{\text {substrate }}$ may be calculated from the expression in eq 4 .

$Q_{\text {substrate }}=n_{2} C_{\mathrm{AA}} V F$

The parameter $n_{2}$ is the number of electrons involved in the oxidation process in eq 3 (i.e. $n_{2}=8$ ) and $C_{\mathrm{AA}}$ is the initial concentration of $\mathrm{AA}$ in the anodic chamber.

\section{Results and discussion}

\subsection{Catalytic mechanism of dehalogenation using CoTPP}

\subsubsection{Homogeneous catalysis in DMF}

The elucidation of the behavior of electrocatalysts under homogeneous conditions is crucial to obtain a mechanistic understanding of the electron transfer processes in dehalogenation reactions. The cyclic voltammogram of CoTPP catalyst shows two well defined redox couples with reduction peaks at $-0.77\left(\mathrm{Co}^{\mathrm{II}}\right.$ to $\left.\mathrm{Co}^{\mathrm{I}}\right)$ and $-1.92 \mathrm{~V}\left(\mathrm{Co}^{\mathrm{I}}\right.$ to 
$\left.\mathrm{Co}^{0}\right)$ and on the reverse sweep two oxidation peaks at $-1.85\left(\mathrm{Co}^{0}\right.$ to $\left.\mathrm{Co}^{\mathrm{I}}\right)$ and $-0.71 \mathrm{~V}$ $\left(\mathrm{Co}^{\mathrm{I}}\right.$ to $\left.\mathrm{Co}^{\mathrm{II}}\right)$ (Figure $\left.\mathrm{S} 4\right)$. Addition of TCAA gives rise to a pre-catalytic peak at $-0.67 \mathrm{~V}$ prior to the electrochemical generation of Co $\mathrm{IPP}$ at $-0.77 \mathrm{~V}$ (Figure 2). This indicates the very high catalytic activity of $\mathrm{Co}^{\mathrm{I}}$ towards the first dechlorination step of TCAA.

In comparison, the indirect reduction of DCAA shows up at the potential of electrogenerated $\mathrm{Co}^{\mathrm{I}} \mathrm{TPP}$ at $-0.77 \mathrm{~V}$ (Figure 2). For MCAA no catalytic peaks are observable before the occurrence of the reduction of $\mathrm{Co}^{\mathrm{I}} \mathrm{TPP}$ to $\mathrm{Co}^{0} \mathrm{TPP}$ at $-1.9 \mathrm{~V}$, although the current after the electrogeneration of $\mathrm{Co}^{\mathrm{I}} \mathrm{TPP}$ keeps increasing from $-1.1 \mathrm{~V}$ (Figure S5). The latter feature would suggest that Co'TPP also shows a certain catalytic activity towards the reduction of MCAA (vide infra).

Overall, the catalytic activity of CoTPP decreases going from TCAA to DCAA and further to MCAA (Figure 2). This is as expected considering that the formal oxidation state of carbon atoms becomes higher as the number of directly attached halogen atoms increases, thus making such molecules more susceptible to a reductive dehalogenation [22]. Although electrogenerated $\mathrm{Co}^{0} \mathrm{TPP}$ at $-1.9 \mathrm{~V}$ under homogeneous conditions can greatly boost the full dehalogenation (Figure S5), the profound concurrent hydrogen evolution accompanying (more negative than $-1.2 \mathrm{~V}$, Figure 3 ) would make it impractical for water treatment. Another issue is the complicated procedures to separate the catalyst, reactants, and products that are mixed in the homogeneous solution. Hence, heterogeneous catalysis in water with the catalyst coated onto the electrode is needed for practical applications. 


\subsubsection{Heterogeneous catalysis in water}

Figure 3 shows the linear sweep voltammograms recorded on a GC electrode, where CoTPP was deposited using an ink containing CB to increase the conductivity. Among all the conductive carbon materials, $\mathrm{CB}$ is the cheapest. For this reason it has already found use as catalyst support in industrial applications [23]. The XPS spectra and elemental composition of CoTPP/CB catalyst are shown in Figure S6 and Table S2, respectively.

In linear sweep voltammetry, adding TCAA to the electrolyte solution results in the appearance of three successive reduction peaks at $-0.55,-0.8$, and $-1.1 \mathrm{~V}$, assigned to the three sequential electrocatalytic dehalogenation reactions converting TCAA $\rightarrow$ DCAA $\rightarrow$ MCAA. In comparison, for DCAA the last two reduction peaks and for MCAA the last reduction peak are the only ones observed, confirming the sequential dehalogenation processes. The reduction peaks of TCAA $(-0.55 \mathrm{~V})$ and DCAA $(-0.8 \mathrm{~V})$ correspond well with those obtained under homogeneous conditions for TCAA (onset potential at $-0.5 \mathrm{~V}$ ) and DCAA (catalytic peak at $-0.77 \mathrm{~V}$ ), respectively. In contrast, the reduction peak of MCAA occurs at a substantially less negative potential under heterogeneous than homogeneous conditions ( $-1.1 \mathrm{vs}-1.9 \mathrm{~V})$, although, in the latter case a raise in the current, in fact, starts to be noted already at $-0.8 \mathrm{~V}$ (Figure S5). It is not surprising that the exact environment exerts a marked influence on the reactivity of a given catalyst, i.e. it matters greatly, if the catalyst is deposited in a polymer matrix or is freely diffusing in a solvent, let alone if water or DMF is the medium of choice.

Addition of even more TCAA reveals that the catalytic peak current increases with the TCAA concentration, until at least $25 \mathrm{mM}$ (Figure $4 \mathrm{a}$ ). This demonstrates that the 
reductive dehalogenation process catalyzed by CoTPP/CB is fast and not limited by the chemical reaction in the concentration range employed. In addition, the catalytic peak current increases linearly with the square root of the scan rate indicating that the reaction is diffusion controlled (Figure 4b).

\subsection{Utilization of bio-generated electricity for dehalogenation}

Figure 1a depicts the schematic illustration of a MFC-powered reactor for reductive dehalogenation. When the MFC runs at open circuit, the cathodic potential is at $-0.003 \mathrm{~V}$, where the catalyst is on the redox form $\mathrm{Co}^{\mathrm{II}} \mathrm{TPP}$. Control experiments running over 1 week at open circuit showed no TCAA removal or generation of any reduction products. Connecting a $10 \Omega$ resistor between the bio-anode and the cathode resulted in a change of the potential of the cathode to $-0.45 \mathrm{~V}$, while passing a $0.3 \mathrm{~mA}$ current. It demonstrated the bio-generated electricity was used for dehalogenation.

To deduce the extent by which this energy may be used for reductive dehalogenation, an electrolysis was carried out at $-0.45 \mathrm{~V}$ for $60 \mathrm{~h}$ in a $2 \mathrm{mM} \mathrm{Na} 2 \mathrm{SO}_{4}$ aqueous solution containing $250 \mu \mathrm{M}$ TCAA using the CoTPP/CB catalyst. The reduction product mixture was analyzed by IC. Gratifyingly, an analysis of the product mixture showed that the TCAA concentration dropped by $10 \%$ from 250 to $216 \mu \mathrm{M}$, while the carbon and chloride mass balances confirmed the formation of DCAA $(30 \pm 1 \mu \mathrm{M})$, MCAA $(11 \pm 0$ $\mu \mathrm{M})$ and $\mathrm{Cl}^{-}(60 \pm 18 \mu \mathrm{M})$ as the only products (Figure 5).

Nevertheless, the developed cell does not work optimally, in that the dehalogenation rate is relatively slow and, at the same time, the formation of partial dechlorinated products would be toxic to most microorganisms. For this reason the fully dehalogenated 
product, acetic acid (AA), is desired for the subsequent energy capture (vide infra). One possible solution could be to consider more reactive metal macrocycle-featured coenzymes to achieve the full dehalogenation at potentials around $-0.4 \mathrm{~V}$ [24]. Unfortunately, enzyme-based catalysts suffer from poor stability and high cost. For real applications, a much more feasible solution would be to use an external energy source or, preferentially, the onsite produced electricity at some wastewater treatment plants to augment the cathode potential [25].

In this work, an external power supply was used first to achieve a cathodic potential of $-0.8 \mathrm{~V}$ in a MEC (Figure 1b). The cyclic voltammetric studies revealed that the catalytic reduction of DCAA to MCAA occurs at exact this potential (Figure 3). Electrolysis at $-0.8 \mathrm{~V}$ for $8 \mathrm{~h}$ resulted in 58\% TCAA removal with concentrations decreasing from 250 $\mu \mathrm{M}$ to $108 \pm 3 \mu \mathrm{M}$, accompanied with formation of $127 \pm 1 \mu \mathrm{M}$ DCAA, $11 \pm 0 \mu \mathrm{M}$ MCAA, $19 \pm 0 \mu \mathrm{M} \mathrm{AA}$, and $189 \pm 10 \mu \mathrm{M} \mathrm{Cl}^{-}$as the products (Figure 6a). The formation of AA at this potential indicates that a slow conversion of MCAA may take place prior to the catalytic reduction peak recorded in cyclic voltammetry at $-1.1 \mathrm{~V}$ (Figure 3). Carrying out an $8 \mathrm{~h}$ electrolysis at $-1.1 \mathrm{~V}$ promoted a complete conversion of $250 \mu \mathrm{M}$ TCAA to $121 \pm 2 \mu \mathrm{M}$ DCAA, $78 \pm 4 \mu \mathrm{M}$ MCAA, $15 \pm 2 \mu \mathrm{M} \mathrm{AA}$, and $322 \pm 7 \mu \mathrm{M} \mathrm{Cl}^{-}$ (Figure 6b).

In these experiments both the carbon and $\mathrm{Cl}$ mass balances demonstrate the sequential dehalogenation of TCAA with DCAA and MCAA as the only intermediates. Hence, the electrochemical analysis and MEC electrolysis data confirm that the electrogenerated Co IPP can dehalogenate HAAs in water with the reaction rate decreasing in the order TCAA > DCAA > MCAA. 


\subsection{Sustainability of the self-dehalogenation process}

A sustainable dehalogenation process requires electricity generation and augmentation of the cathodic potential from the dehalogenated products within the system. The nutrients-added fully dehalogenated product AA can then be transferred to the anolyte to produce electricity for a new round of dehalogenation in the cathodic chamber. The chemical energy of the dehalogenated products can be captured as electricity in a MFC (Figure S2 and Figure S3), while the augmentation of the cathodic potential can be provided by stacked MFCs powered by the dehalogenated products [26].

Table 1 shows the effect of a stacked MFC+MEC configuration on the cathodic potential in the MEC. Since the full dehalogenation product AA would first be observed with the cathodic potential $<-0.8 \mathrm{~V}$ in MEC (vide supra), a configuration consisting of 3 MFC and 1 MEC was first investigated. However, from Figure 7a it is clear that the cathodic potential becomes $>-0.8 \mathrm{~V}$ after $116 \mathrm{~h}$ reaction with an almost complete cease in the dehalogenation process as the consequence. The underlying reason for this is the consumption of AA by exoelectrogenic bacteria in the anodic chamber after $\sim 110 \mathrm{~h}$. Moreover, this in line with the observation on the potential drop shown in Figure S2.

Thus, a more negative cathodic potential is needed for full conversion of MCAA to AA within $\sim 110 \mathrm{~h}$ and a $6 \mathrm{MFC}+\mathrm{MEC}$ configuration was considered next. Encouragingly, this results in a cathodic potential of $\sim-1.1 \mathrm{~V}$, at which the catalytic reduction peak of MCAA to AA was observed by cyclic voltammetry (Figure 3). Under these conditions the full reduction of MCAA to AA in the catholyte in MEC took $144 \mathrm{~h}$ giving a pseudo firstorder reaction rate constant of $0.044 \mathrm{~h}^{-1}$ (Figure $7 \mathrm{~b}$ ). The nutrients-added fully dehalogenated product AA was then transferred to the anolyte to produce electricity for a 
new round of dehalogenation. This result demonstrates the first bioelectrochemical system that could use the bio-generated electricity derived from electrogenic microorganisms to achieve self-sustaining dehalogenation. Hence, with this setup we successfully accomplished our aim of developing a proof-of-concept system, where the energy of biodegradable compounds-generated from bio-refractory halogenated pollutants-is captured via exoelectrogenic bacteria and may further be used to drive the conversion process. It should be noted that the sustainability of such system should be further verified using a continuous flow system.

But how close is the stacked system then to be $100 \%$ self-sustaining, if that was the ultimate goal? Theoretically, oxidation of one mole AA can produce eight mole of electrons while the conversion of MCAA to AA only requires two mole of electrons. A fully sustainable self-dehalogenation process is therefore expected if a $25 \%$ overall Faradaic efficiency (FE) can be obtained. In this work, the $\mathrm{FE}_{\text {cathode }}$ was determined to be $32.7 \%$ according to eq 1 , since most electrons go to the hydrogen evolution reaction. The $\mathrm{FE}_{\text {anode }}$ was determined to be $33 \%$ (according to eq 2 ) due to the fact that a mixed bacteria culture was used in this work [20], rather than a pure culture which has been reported to reach an efficiency as high as $98.6 \%$ [27]. The overall $\mathrm{FE}\left(\mathrm{FE}_{\text {cathode }} \times \mathrm{FE}_{\text {anode }}\right)$ was calculated to be $10.8 \%$. Thus, the use of selected strains would, in fact, enable the requested increase in $\mathrm{FE}_{\text {anode }}$ to make the overall $\mathrm{FE}$ surpass the $25 \%$, the minimum value for a self-sustaining process. In other words, our work demonstrates that the overall efficiency of the final set-up is not far from what is required for reaching a self-sustainable process, if that would be the goal. The price to pay would be a lowering of the cost-effectiveness of the process. 
This sustainable concept developed in this work can be generalized to other MFCbased technologies for bio-refractory pollutant removal including those using the MFCFenton process [18]. The converted pollutant with increased biodegradability can be used to feed the exoelectrogenic bacteria in MFC-Fenton or other bioelectrochemical systems, thereby allowing the energy to be harvested. In the best case, the potential augmentation needed in the system could be provided by the electricity produced onsite in the same wastewater treatment plant from biogas via anaerobic sludge digestion [28] or the MFC as shown in this work [29]. In this manner a sustainable treatment process for biorefractory wastewater is envisioned.

The recycling process reported in this work would not be ideal for treatment of bio-refractory pollutants present in low concentrations. This would fail to provide sufficient organic matter substrate for bacterial growth. However, it is applicable for industrial wastewater having high concentrations of bio-refractory pollutants that are converted to high-concentration bio-degradable substrates. In particular, the technique may find its use for carbon-rich domestic wastewater with low concentration of biorefractory pollutants. This situation is common in most areas where domestic wastewater and industrial wastewater are collected without discrete treatment facilities. The detoxification with a proper catalyst results in a carbon-rich biodegradable wastewater for a sustainable water treatment process.

Batch mode was adopted here to prove the concept while continuous operation could bring more accurate data for biofilm growth and metabolism, and stable system performance. It should be noted that energy consumption for the stirrer power and temperature control were not counted here, though it is required by many other treatment 
technologies/processes. In practical application, the stirring could be omitted in continuous mode where the wastewater flow is always there when they are received in wastewater treatment plants. Temperature control may be also not needed as bioelectrochemical system may function over a large temperature range (from 4 to 55 $\left.{ }^{\circ} \mathrm{C}\right)$. A more accurate energy analysis could be investigated in future to further develop the technology.

For practical applications, a capacitor could be used to store the electrical energy generated from MFC stacks running in continuous mode and subsequently use the electronic circuit to discharge voltage within the cathode chamber of a "conventional" MFC in the cascade (essentially change it in situ into a "temporary" MEC). In this way, extra MEC reactor can be omitted and thereby reduce the construction and operational costs.

\section{Conclusion}

Energy-intensive chemical/physical processes are the classical techniques to mineralize, sorb, or otherwise transform toxic bio-refractory organic pollutants. Here, we report for the first time an example of successful self-sustaining electrochemical waste water treatment process based on microbial energy capture from organic matter converted from bio-refractory halogenated organic pollutants. A fully dehalogenated product (AA) is formed with supply of additional $0.35 \mathrm{~V}$ which may be provided onsite from the MFC. Stacked MFCs are used to augment the cathodic potential in MEC to $-1.1 \mathrm{~V}$ and achieve full dehalogenation of MCAA to AA. The AA can be recycled to feed the bacteria in MFC and MEC. Our results show that the Faradaic efficiency achieved under cost- 
effective conditions is very close to that required for an energy-sustainable selfdehalogenation process.

\section{Acknowledgements}

This work was funded by Danish council for independent research, DFF-Individual postdoctoral grants (DFF-4093-00295, SSI-G-X). We are deeply appreciative of the generous financial support from the Danish National Research Foundation (grant no. DNRF118). We thank Xiangdan Jin from Department of Environmental Engineering, Technical University of Denmark for the help with MFC assembling.

\section{Author contributions statement}

L. Huang, Y. Zhang, X. Hu, H. Hansen, S. Pedersen, and K. Daasbjerg conceived the experiment. L. Huang and Y. Zhang conducted the experiment. X. Hu help with the sampling and some analysis. L. Huang drafted the manuscript, and all authors have contributed to the revision. All authors have given approval to the final version of the manuscript.

\section{Additional information}

Competing financial interests: The authors declare no competing financial interests.

\section{Data availability statement}

All the data are available.

\section{References}

[1] P.L. McCarty, J. Bae, J. Kim, Domestic wastewater treatment as a net energy producer-can this be achieved?, Environ. Sci. Technol. 45 (2011) 7100-7106. 
[2] B.E. Logan, K. Rabaey, Conversion of wastes into bioelectricity and chemicals by using microbial electrochemical technologies, Science 337 (2012) 686-690.

[3] E.S. Heidrich, T.P. Curtis, J. Dolfing, Determination of the internal chemical energy of wastewater, Environ. Sci. Technol. 45 (2011) 827-832.

[4] W.-W. Li, H.-Q. Yu, Z. He, Towards sustainable wastewater treatment by using microbial fuel cells-centered technologies, Energy Environ. Sci. 7 (2014) 911-924.

[5] H. Liu, B.E. Logan, Electricity generation using an air-cathode single chamber microbial fuel cell in the presence and absence of a proton exchange membrane, Environ. Sci. Technol. 38 (2004) 4040-4046.

[6] B.E. Logan, B. Hamelers, R.A. Rozendal, U. Schrorder, J. Keller, S. Freguia, P. Aelterman, W. Verstraete, K. Rabaey, Microbial fuel cells: Methodology and technology, Environ. Sci. Technol. 40 (2006) 5181-5192.

[7] M. Pera-Titus, V. Garcia-Molina, M.A. Banos, J. Gimenez, S. Esplugas, Degradation of chlorophenols by means of advanced oxidation processes: a general review, Appl. Catal., B 47 (2004) 219-256.

[8] J.J. Pignatello, E. Oliveros, A. MacKay, Advanced oxidation processes for organic contaminant destruction based on the Fenton reaction and related chemistry, Crit. Rev. Environ. Sci. Technol. 36 (2006) 1-84.

[9] M.L. Hanson, K.R. Solomon, Haloacetic acids in the aquatic environment. Part I: macrophyte toxicity, Environ. Pollut. 130 (2004) 371-383.

[10] Y. Hong, H. Song, T. Karanfil, Formation of haloacetic acids from dissolved organic matter fractions during chloramination, Water Res. 47 (2013) 1147-1155. 
[11] F.W. Pontius, Complying with future water regulations, J.-Am. Water Works Assoc. 91 (1999) 46-58.

[12] J. Radjenovic, D.L. Sedlak, Challenges and opportunities for electrochemical processes as next-generation technologies for the treatment of contaminated water, Environ. Sci. Technol. 49 (2015) 11292-11302.

[13] L. Ukrainczyk, M. Chibwe, T.J. Pinnavaia, S.A. Boyd, Reductive dechlorination of carbon tetrachloride in water catalyzed by mineral-supported biomimetic cobalt macrocycles, Environ. Sci. Technol. 29 (1995) 439-445.

[14] G.M. Klečka, S.J. Gonsior, Reductive dechlorination of chlorinated methanes and ethanes by reduced iron (II) porphyrins, Chemosphere 13 (1984) 391-402.

[15] U.E. Krone, K. Laufer, R.K. Thauer, H.P.C. Hogenkamp, Coenzyme-F430 as a possible catalyst for the reductive dehalogenation of chlorinated-C1 hydrocarbons in methanogenic bacteria, Biochemistry 28 (1989) 10061-10065.

[16] U.E. Krone, R.K. Thauer, H.P.C. Hogenkamp, Reductive dehalogenation of chlorinated C1-hydrocarbons mediated by corrinoids, Biochemistry 28 (1989) 49084914.

[17] T.S. Marks, J.D. Allpress, A. Maule, Dehalogenation of lindane by a variety of porphyrins and corrins, Appl. Environ. Microbiol. 55 (1989) 1258-1261.

[18] C.-H. Feng, F.-B. Li, H.-J. Mai, X.-Z. Li, Bio-electro-Fenton process driven by microbial fuel cell for wastewater treatment, Environ. Sci. Technol. 44 (2010) 18751880.

[19] C.A. Amatore, A. Jutand, F. Pflüger, Nanosecond time resolved cyclic voltammetry: Direct observation of electrogenerated intermediates with bimolecular diffusion 
controlled decay using scan rates in the megavolt per second range, J. Electroanal. Chem. Interfacial Electrochem. 218 (1987) 361-365.

[20] Y.F. Zhang, I. Angelidaki, Counteracting ammonia inhibition during anaerobic digestion by recovery using submersible microbial desalination cell, Biotechnol. Bioeng. $112(2015)$ 1478-1482.

[21] H. Liu, S. Grot, B.E. Logan, Electrochemically assisted microbial production of hydrogen from acetate, Environ. Sci. Technol. 39 (2005) 4317-4320.

[22] T.M. Vogel, C.S. Criddle, P.L. McCarty, ES Critical Reviews: Transformations of halogenated aliphatic compounds, Environ. Sci. Technol. 21 (1987) 722-736.

[23] E. Auer, A. Freund, J. Pietsch, T. Tacke, Carbons as supports for industrial precious metal catalysts, Appl. Catal., A 173 (1998) 259-271.

[24] Y.-P. Li, H.-B. Cao, Y. Zhang, Reductive dehalogenation of haloacetic acids by hemoglobin-loaded carbon nanotube electrode, Water Res. 41 (2007) 197-205.

[25] A.V. A/S, Egaa wastewater treatment plant - the first in the world to produce 50 percent more electricity than it uses, 2017.

[26] P. Aelterman, K. Rabaey, H.T. Pham, N. Boon, W. Verstraete, Continuous electricity generation at high voltages and currents using stacked microbial fuel cells, Environ. Sci. Technol. 40 (2006) 3388-3394.

[27] D.R. Bond, D.R. Lovley, Electricity production by Geobacter sulfurreducens attached to electrodes, Appl. Environ. Microbiol. 69 (2003) 1548-1555.

[28] A. Abusoglu, S. Demir, M. Kanoglu, Thermoeconomic assessment of a sustainable municipal wastewater treatment system, Renewable Energy 48 (2012) 424-435. 
[29] M.A. Rodrigo, P. Cañizares, J. Lobato, R. Paz, C. Sáez, J.J. Linares, Production of electricity from the treatment of urban waste water using a microbial fuel cell, J. Power Sources 169 (2007) 198-204.

\section{Figures captions}

Figure 1. Schematic illustration of (a) microbial fuel cell, (b) microbial electrolysis cell, and (c) stacked microbial fuel cells powering microbial electrolysis cell for reductive dehalogenation. The dashed gray line represents a cation exchange membrane. The dot blue line with arrow in (c) represent recycling of the acetic acid produced from catholyte to anolyte.

Figure 2. Cyclic voltammograms recorded at a GC disk electrode (diameter $=1 \mathrm{~mm})$ of 1 mM CoTPP (black), 1 mM CoTPP + 1 mM TCAA (red), 1 mM CoTPP + 1 mM DCAA (blue), and $1 \mathrm{mM}$ CoTPP $+1 \mathrm{mM}$ MCAA (orange) using a scan rate of $0.1 \mathrm{~V} \mathrm{~s}^{-1}$ in $0.1 \mathrm{M}$ $\mathrm{Bu}_{4} \mathrm{NBF}_{4} / \mathrm{DMF}$.

Figure 3. Linear sweep voltammograms recorded at a GC plate electrode coated with CoTPP/CB using a scan rate of $0.1 \mathrm{~V} \mathrm{~s}^{-1}$ in $0.5 \mathrm{M} \mathrm{Na}_{2} \mathrm{SO}_{4}$ aqueous solution containing bare electrolyte (black), $5 \mathrm{mM}$ TCAA (blue), $5 \mathrm{mM}$ DCAA (red), and $5 \mathrm{mM}$ MCAA (orange).

Figure 4. Cyclic voltammograms recorded at a CoTPP/CB coated GC plate electrode (a) using a scan rate of $0.1 \mathrm{~V} \mathrm{~s}^{-1}$ in $0.5 \mathrm{M} \mathrm{Na}_{2} \mathrm{SO}_{4}$ aqueous solution with increasing TCAA concentration from $5,10,15,20,25 \mathrm{mM}$, (b) in $0.5 \mathrm{M} \mathrm{Na}_{2} \mathrm{SO}_{4}+5 \mathrm{mM}$ TCAA aqueous solution using increasing scan rate from $0.01,0.05,0.1,0.2,0.5$ to $1 \mathrm{~V} \mathrm{~s}^{-1}$; Inset shows 
the peak current recorded at $-1.2 \mathrm{~V}$ vs. square root of the scan rate. Conditions: effective working electrode area $=0.5 \mathrm{~cm}^{2}, 40 \mu \mathrm{L} \mathrm{cm}{ }^{-2}$ catalyst ink drop casting.

Figure 5. Reduction kinetics of TCAA $\left([\mathrm{TCAA}]_{0}=250 \mu \mathrm{M}, 2 \mathrm{mM} \mathrm{Na}_{2} \mathrm{SO}_{4}\right.$, initial $\mathrm{pH}=$ $6.4, E_{\text {cathode }}=-0.45 \mathrm{~V}$ ) showing the product distribution in the cathodic compartment of a microbial fuel cell. The open symbols present the carbon and chloride mass balances during the reaction course. Error bars represent standard error of triplicates.

Figure 6. Reduction kinetics of TCAA $\left([\mathrm{TCAA}]_{0}=250 \mu \mathrm{M}, 2 \mathrm{mM} \mathrm{Na}_{2} \mathrm{SO}_{4}\right.$, initial $\mathrm{pH}=$ 6.4) showing the product distribution in the cathodic compartment of a microbial electrolysis cell, where a power supply is used to augment the cathodic potential to (a) $-0.8 \mathrm{~V}$, and (b) $-1.1 \mathrm{~V}$. The open symbols present the carbon and chloride mass balances during the reaction course. Error bars represent standard error of triplicates.

Figure 7. Conversion of MCAA to AA in the cathodic compartment of a microbial electrolysis cell, where (a) three and (b) six microbial fuel cells are stacked and used to augment the cathodic potential (catholyte: $300 \mathrm{~mL} 17 \mathrm{mM}$ MCAA in $50 \mathrm{mM}$ phosphate buffer ( $\mathrm{pH}$ 7) aqueous solution; anolyte: nutrient-containing dehalogenated catholyte; the data are fitted with $1^{\text {st }}$ order kinetics).

\section{Table captions}

Table 1. Cathodic potential, $E_{\text {cathode }}$, in the MEC measured for various MFC/MEC configurations $\left(\mathrm{V}_{\mathrm{MCAA}}=0.3 \mathrm{~L},[\mathrm{MCAA}]=17 \mathrm{mM}, \mathrm{S}_{\text {cathode }}=50 \mathrm{~cm}^{2}\right)$. 
Table 1.

\begin{tabular}{cc}
\hline Configuration & $E_{\text {cathode }}(\mathrm{V}$ vs. $\mathrm{Ag} / \mathrm{AgCl})$ \\
\hline MEC & -0.45 \\
MFC+MEC & -0.65 \\
2MFC+MEC & -0.78 \\
3MFC+MEC & -0.88 \\
4MFC+MEC & -0.92 \\
5MFC+MEC & -1.03 \\
6MFC+MEC & -1.15 \\
\hline
\end{tabular}



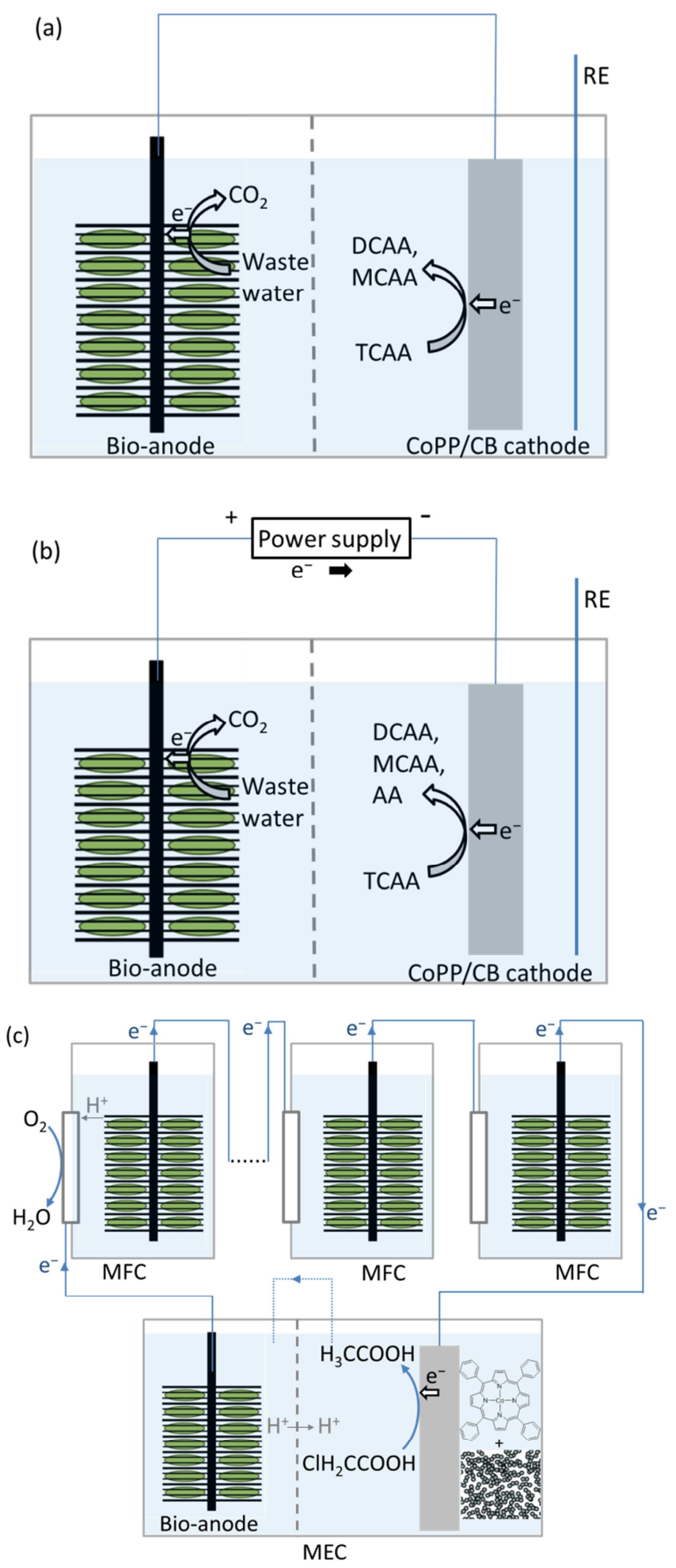

Figure 1 


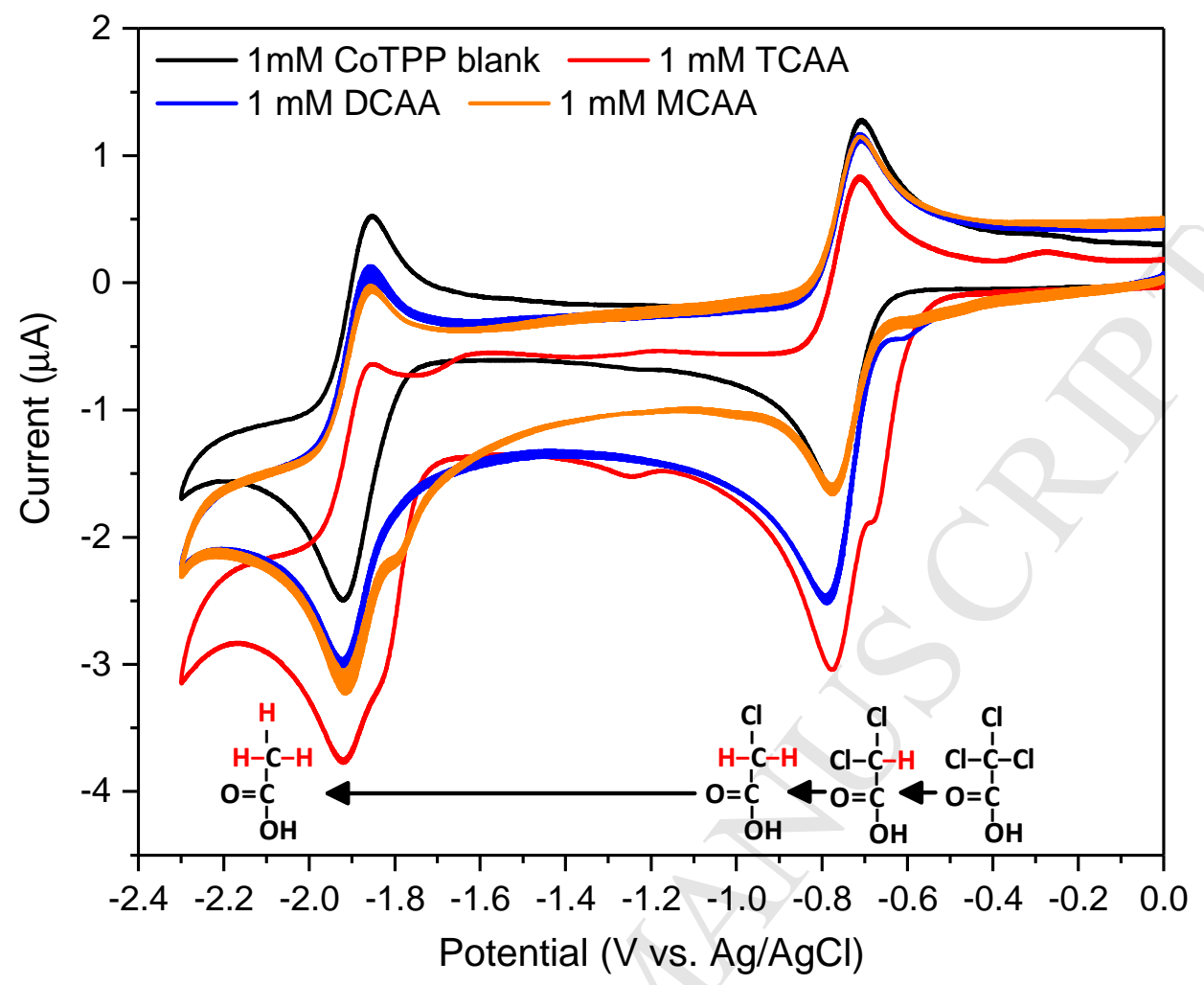

Figure 2. 


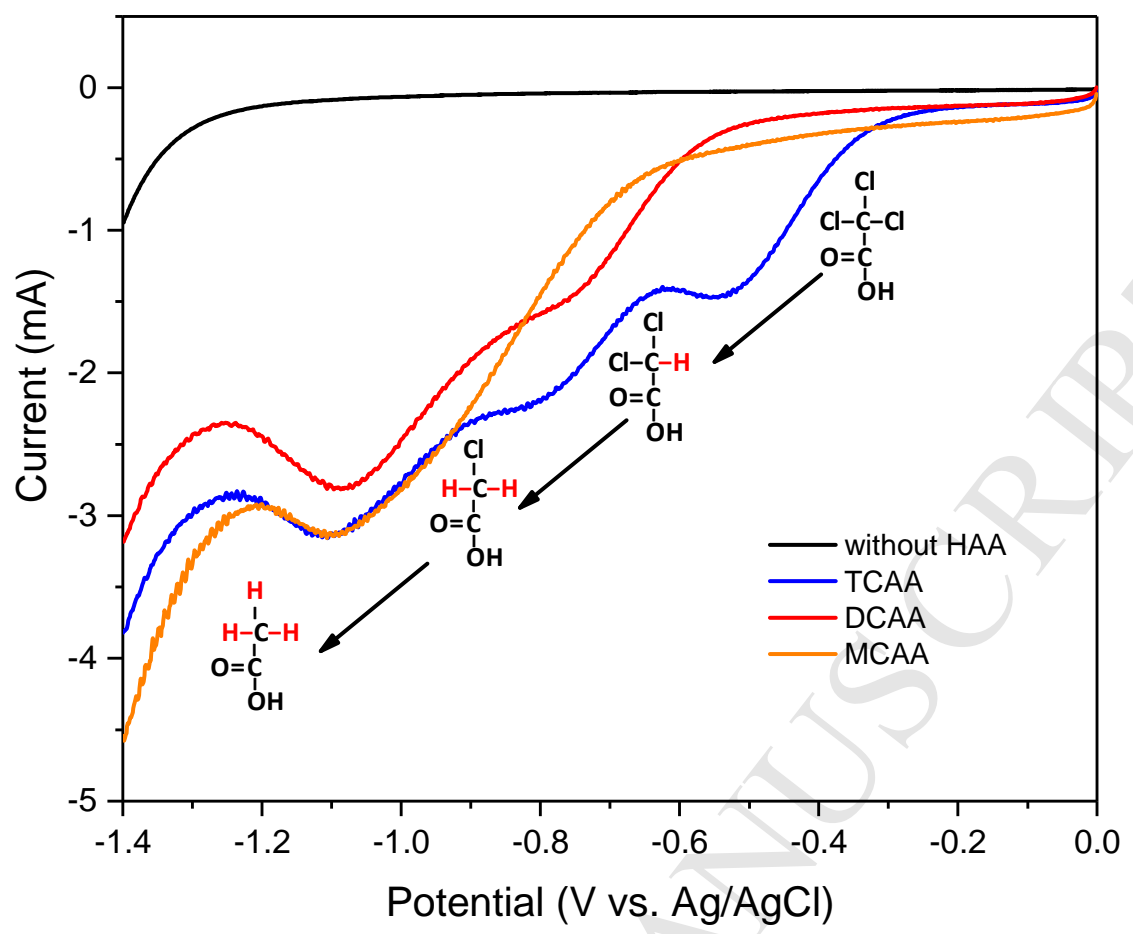

Figure 3. 

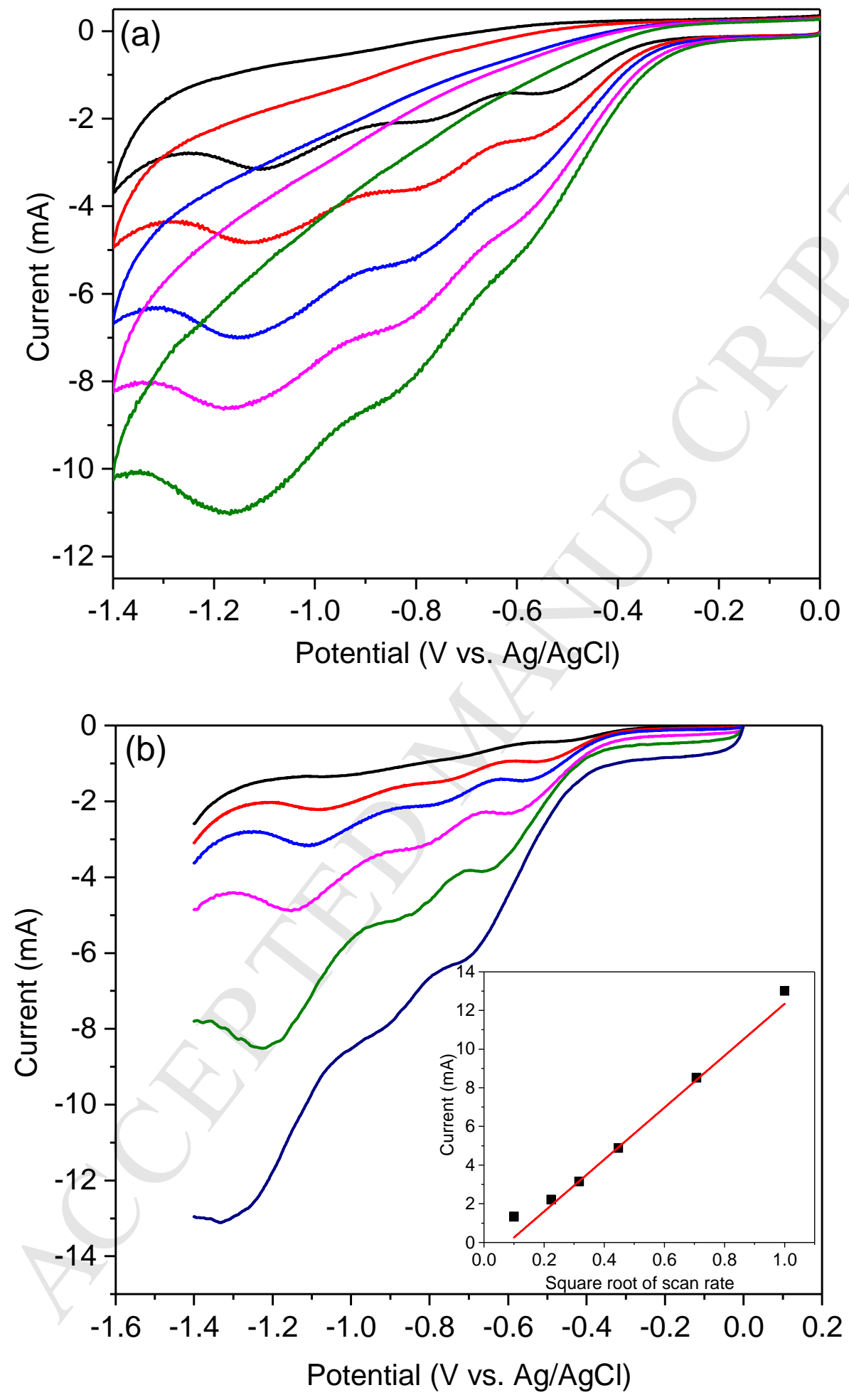

Figure 4. 


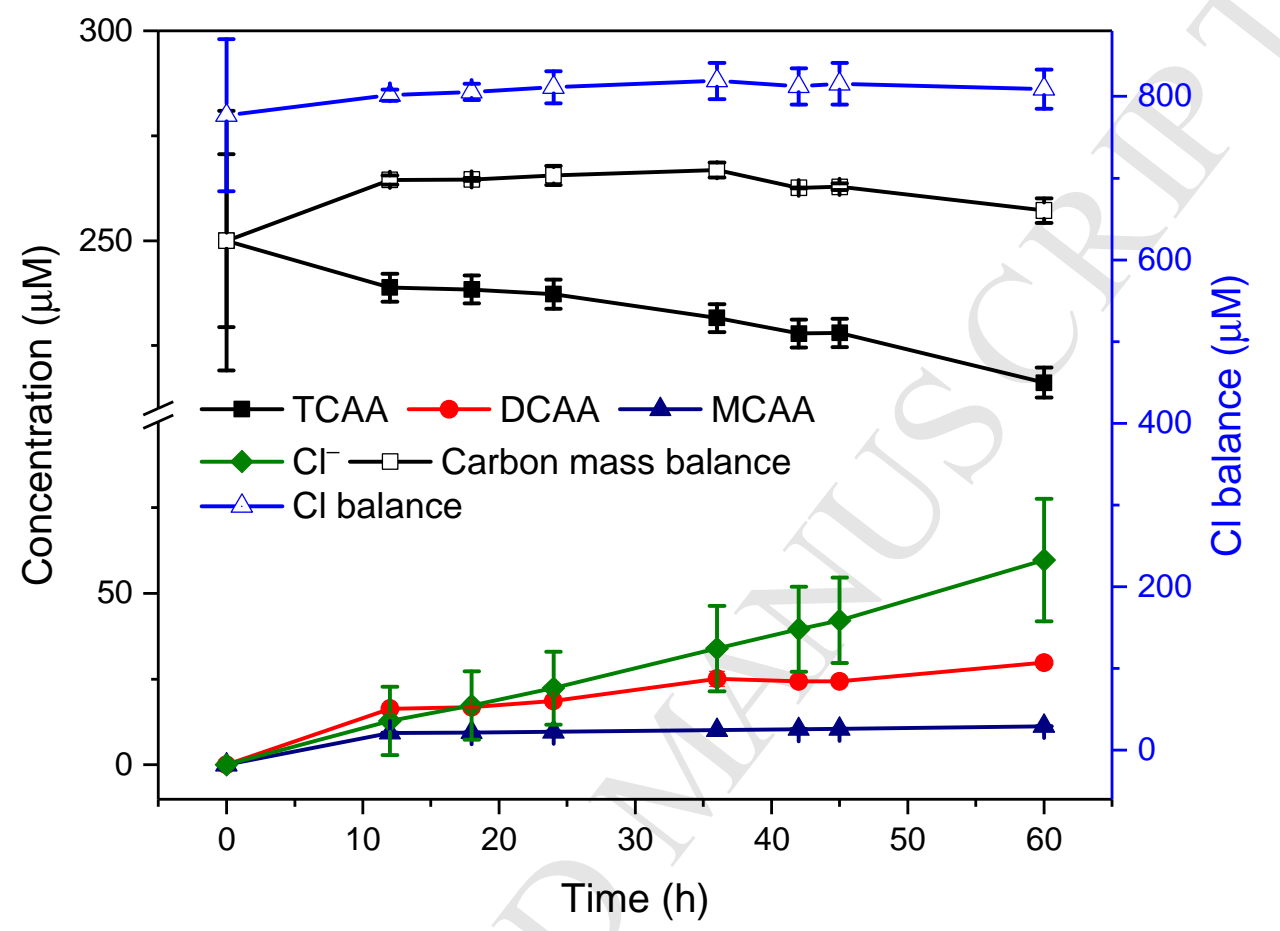

Figure 5 

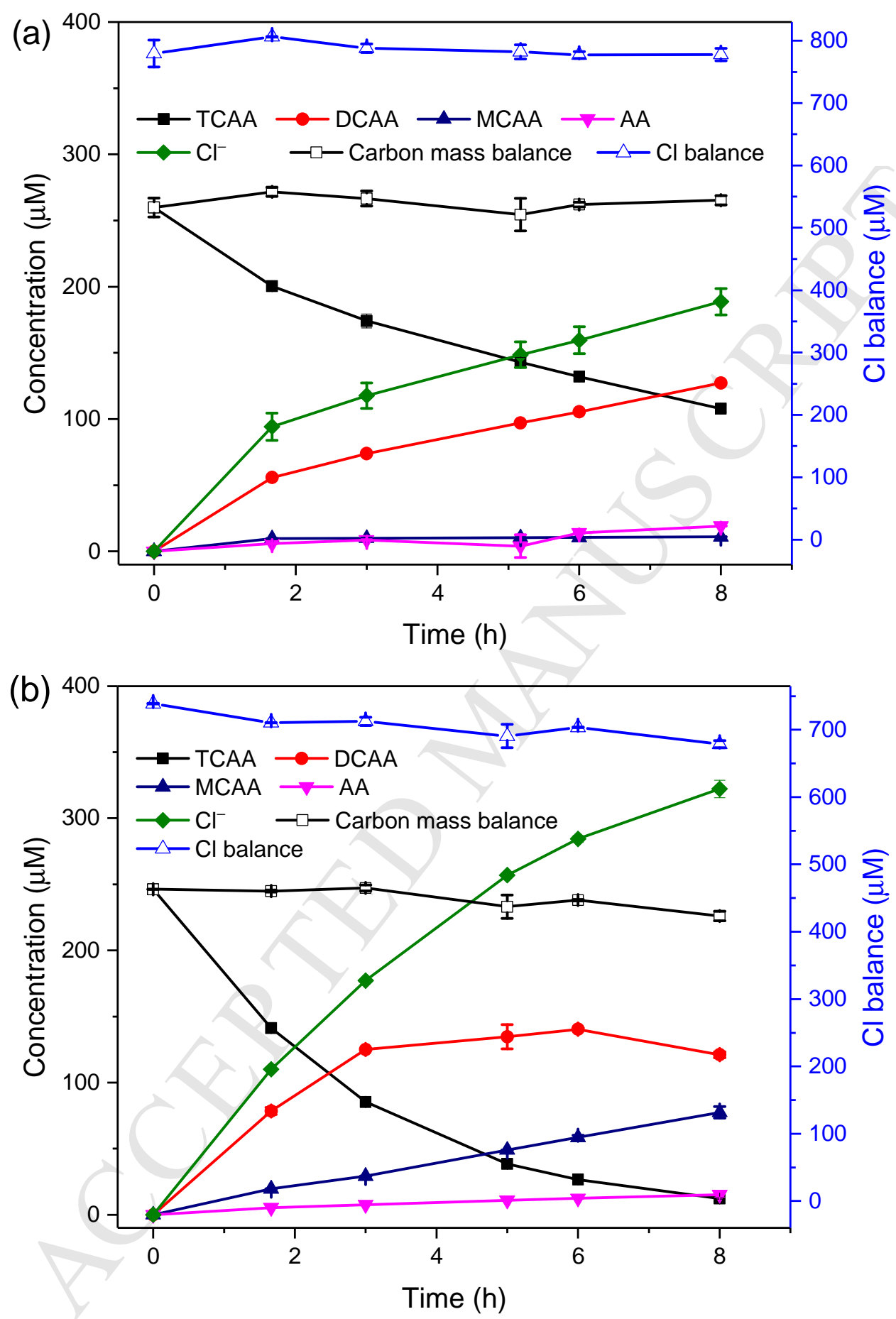

Figure 6 

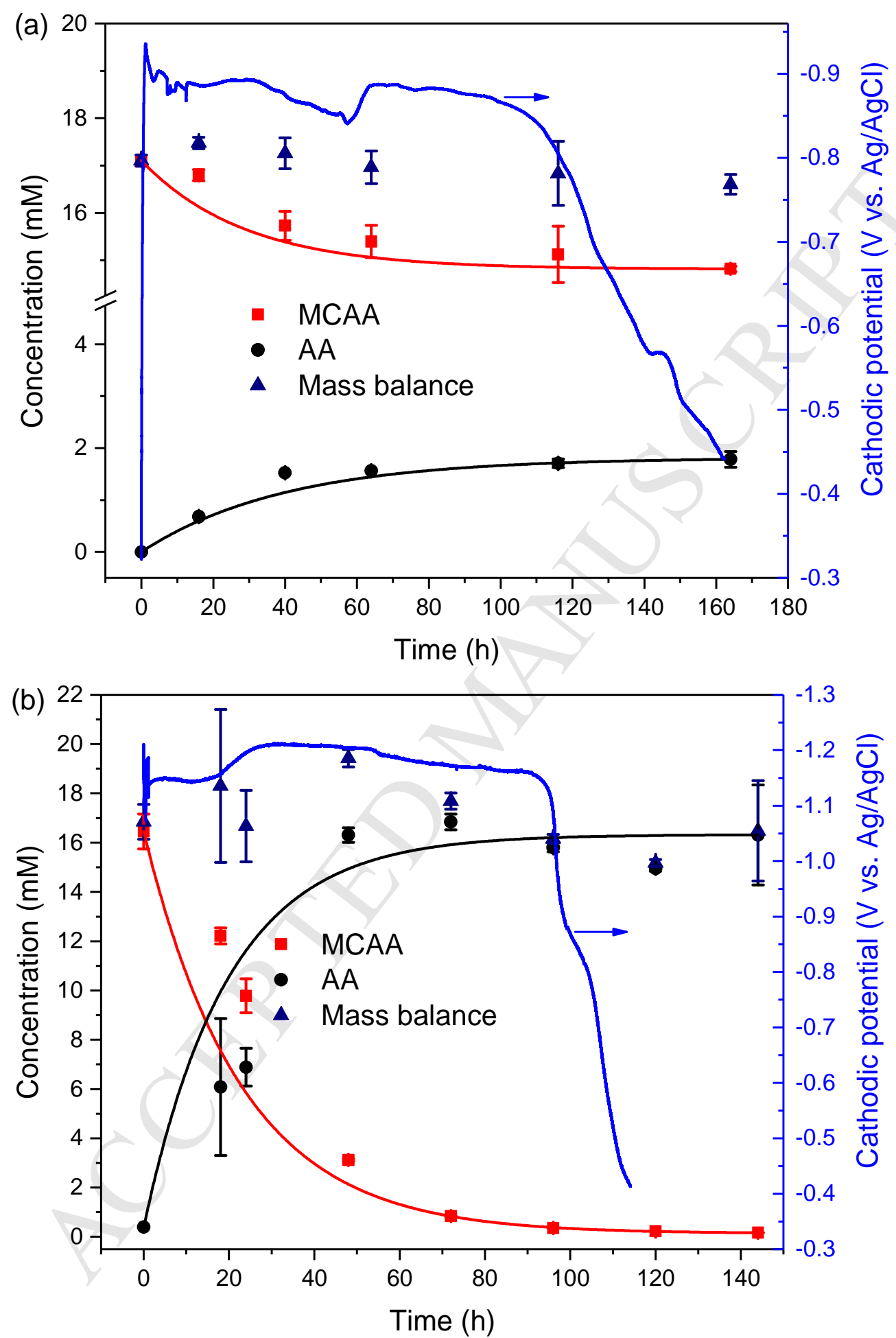

Figure 7 


\section{Highlights}

a) Reductive dehalogenation is powered by a microbial fuel cell.

b) Energy from dehalogenated products is captured by bacteria and used for dehalogenation.

c) Energy efficiency is close to that of a fully sustainable dehalogenation process.

d) Mechanism of cobalt-macrocycle-catalyzed reductive dehalogenation is revealed. 